\title{
Burnt Clay Bricks as an Alternative Filter Media for Pebble Matrix Filters (PMF)
}

\section{C.P.G. Jayalath, N.S. Miguntanna and H.A.K.C. Perera}

\begin{abstract}
A novel method called PMF has proved to be suitable under tropical monsoon conditions for pre-treating high turbidity water before water is introduced to Slow Sand Filters (SSFs). The scarcity of sources of pebbles of the required quality, government regulations on pebble dredging and higher material cost were identified as key problems during the construction of the first ever full scale PMF plant in Sri Lanka at Kataragama. In order to investigate possibilities of utilizing alternative-filter media for PMF, laboratory tests were conducted using different configurations of chips and burnt clay bricks which are available readily in Sri Lanka. Two filter media configurations were tested using a laboratory scaled model at an influent turbidity of $60 \mathrm{NTU}$. The optimum configuration was selected based on the maximum turbidity removal efficiency obtained and was tested by changing influent turbidity. Broken clay bricks with sand in a 1:1 ratio are found to have greater potential as a pre-treatment media for turbidity removal. Moreover, bricks can be utilized as a feasible alternative to natural pebbles. Test results showed that in contrast to chips , turbidity removal efficiency increased with the increment of influent turbidity when bricks were used as the filter media.
\end{abstract}

Keywords: Pebble Matrix Filters (PMF), Sand filters, Bricks, Turbidity.

\section{Introduction}

A newly developed non-chemical and sustainable pre-treatment method called Pebble Matrix Filtration can protect SSFs from high turbidity during heavy monsoon seasons occurring in tropical countries. The PMF has been found to be satisfactory in addressing the high turbidity problem, initially in a laboratory in the United Kingdom, and later infield trials conducted first in Papua New Guinea and subsequently in Montenegro and Serbia [14]. A PMF has two layers namely, the top layer consisting of pebbles and the bottom layer consisting of pebbles and a sand mixture. The upper part consisting of pebbles has a prefiltering effect that removes only a small amount of suspension particles while it is the lower part consisting of the pebble-sand mixed bed that mostly removes the suspension particles.

The Papua New Guinea University of Technology won the World Bank's Development Marketplace Award in 2006 to construct a full-scale PMF unit for the protection of an existing SSF system for the first time in Sri Lanka in collaboration with the National Water Supply and Drainage Board (NWSDB) of Sri Lanka. This system was first implemented in Kataragama and the construction of the plant was completed in May 2008. The river, "Menik Ganga" is the source of water used in the water treatment plant (WTP) at Kataragama and the abstracted water is supplied to four existing SSFs. Additionally, two PMF units, one made of Ferro-cement material and the other made of reinforced concrete have been constructed in the WTP, Kataragama. Three of the SSFs receive raw water directly from the river while the other receives filtrate from the two PMF units[14].

Nevertheless, high filtrate turbidity and low head losses in both filters have been unexpectedly noted and they have severely affected the quality of the water used by consumers in their day to day activities. Wideranging reasons could be attributed to the inefficiency of the PMF. Several physical and hydraulic parameters including pebble size, pebble gradation, pebble material, hydraulic gradient through the matrix, flow rate, initial turbidity, shape and height of the PMF and layer configuration could have caused this problem.

\footnotetext{
Eng. C. P. G. Jayalath, AMIE(Sri Lanka), B.Sc. Eng. (Hons) (Ruhuna), Civil Engineer, Central Engineering Consultancy Bureau.

Eng. N.S. Miguntanna, AMIE(Sri Lanka), B.Sc. Eng. (Hons) (Peradeniya), M.Eng. (QUT), PhD Candidate, University of Wollongong.

Eng. H.A.K.C. Perera, AMIE(Sri Lanka), B.Sc. Eng. (Hons) (Ruhuna), Civil Engineer, Maga Engineering Pvt. $(L t d)$.
} 
During the construction of the first full scale PMF plant in Sri Lanka at Kataragama, problems were encountered in sourcing the required size of pebbles as the filter media. This was due to the high cost and scarcity of the required size of pebbles and the strict government regulations on pebble dredging.

Several research studies have been conducted to investigate an alternative media for PMF to ensure its sustainability. The use of clay balls as an alternative media to natural pebbles was not found to be a viable option due to a number of reasons [9]. For an example, a kiln with high temperature is required to produce clay balls. This incurs an extra cost for preparing specific sizes of clay balls having adequate compressive strength[13]. This research was conducted to evaluate the possibility of using burnt clay brick particles in the PMF as a cost effective and sustainable alternative filter media suitable for tropical countries.

\section{Literature Review}

Pre-treatment processes are generally used to remove settleable solids (SS) from raw water before the water is directed into a SSF, or to coagulation and rapid sand filters in the case of conventional treatment plants. Appropriate pre-treatment systems lessen the load on the SSF unit and yield considerable savings in overall operating costs, especially in respect of those due to chemicals [12]. There are several pre-treatment processes available and their selection depends on a number of criteria such as land availability, cost, degree of treatment required, and the climate. In order to address the problem of high turbid water, PMF has proved to be satisfactory as a non-chemical, and sustainable pre-treatment method that will protect SSFs [11].

\subsection{Turbidity Removal Mechanism of PMF}

The turbidity removal efficiency of a PMF depends on a number of mechanisms. If a particle is larger than the smallest opening through which the water flows, some solids may be removed by a simple mechanical process called physical screening. Two steps are involved in removing other solids, mainly the smaller ones. Firstly, the small particles from the bulk of the fluid within the spaces must be brought close to the surfaces of the grains by a transport mechanism such as gravitational settling. Thereafter, short range surface forces, especially Van der Waal's forces must be favourable for the attachment to occur as particles approach the surface of the grain or formerly deposits solids on the grain. This mechanism is called adsorption.

\subsection{Full Scale Pebble Matrix Plant first built in Sri Lanka.}

The Kataragama WTP is operated by the NWSDB, and serves throughout the year approximately 20,000 regular customers daily and about 2000 additional visitors from other places of Sri Lanka and from overseas during weekends. Another staggering 10,000 pilgrims needs to be served annually during Kataragama festival in July. The total output through the plant is $3500 \mathrm{~m}^{3} /$ day [14].

The Kataragama WTP abstracts water from the river called "Menik Ganga" and SSFs were used for the major filtration process. However, the WTP suffers from occasional monsoonal high turbidity problems with turbidity values reaching above 500 NTU especially during periods of floods. To overcome this problem, two full scale units of PMF were built at Kataragama WTP (See Figure 1) for the first time in Sri Lanka with a total effective plan area of $40 \mathrm{~m}^{2}$ for the pre-treatment of water [14].

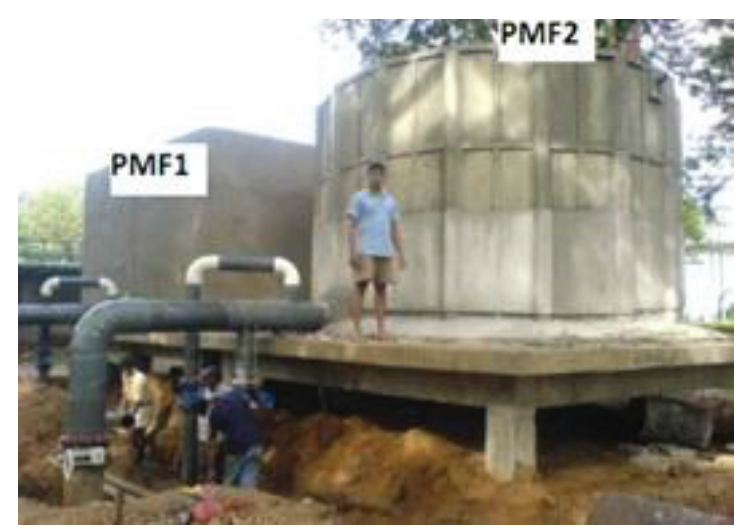

Figure 1- Construction of two PMF Units at the Kataragama WTP (Source [14])

Early research show that the maximum turbidity / SS loading that a SSF can tolerate is about $25 \mathrm{mg} / 1$ (approx. 25-30 NTU) for the preferred operation times (5-6 weeks and more) and that it is about $50 \mathrm{mg} / 1$ (approx. 45-65 NTU) for shorter operation times (2-3 weeks). However, according to test results[14], it has been found that the turbidity of the river "Manik Ganga" was at 137 NTU, plain sedimentation tank influent and effluent were at 94 and 74 NTU respectively and the SSF was at 36 NTU which are much higher than the recommended Sri Lankan drinking water standard of 2 NTU. 
Consequently, it is necessary to protect the SSF from such effects during monsoon or heavy rainfall using pre-treatment methods which are capable of preventing the SSF becoming rapidly clogged and failing to function physically to produce potable water. However, these pretreatment methods have to meet the criteria of simplicity to be suitable for application in rural areas of developing countries, and should preferably avoid the use of chemicals, due to their complexity of handling and dosing, and because of the demands on foreign currency exchange[14].

A SSF has the ability to adsorb/absorb all tastes, odours, colours and a wide range of pollutants which are found in many raw water sources. It is therefore important to keep and sustain SSF technology rather than allowing it to be replaced with Rapid Sand Filtration (RSF) as is the present trend.

\subsection{Key Filtration Variables}

The different effective turbidity removal mechanisms within a filter depend on filtration variables such as filtration velocity, temperature, type of arrangement of gravel packs, size and shape of the filter media, influent characteristics, depth of bed channel etc. [1].The selection of a suitable filtration velocity for filter operation is a critical choice since the filtration efficiency is highly affected by it. The optimum filtration velocity for a given filter depends on different factors, for instance, required water output, filtrate quality, desired run time, maximum head loss and the size and the cost of the filtration unit [6].

Moreover, the filtration process is affected by temperature. It is well known that cold water is always more difficult to filter than warm water. Results of previous studies advocate that the choice of an optimum filter depth must include the influent temperature, as low temperatures require deeper filter beds. The purpose is to provide a sufficient reduction of suspended particles overcoming the low efficiency of the filter at low temperatures[3].

It has been found that small grains have high removal efficiencies; however, they lead to high head loss and short filter runs [10]. In a unisize filter, the bulk of particle removal normally takes place in the upper 10 centimetres of the filter bed while the bottom layers of the bed remain unused. In a rougher bed, the suspension is more uniformly distributed; the head loss and the removal efficiency are relatively low due to high permeability of the grain bed. A media filter size graded was introduced to overcome these problems.

SS concentration and influent turbidity are the main parameters used for monitoring the quality of water entering or leaving a filter. Similarly, these are used to estimate the mass of solids accumulated inside the filter pores over a period of time and to assess the efficiency of the filter.SS plays a significant role in characterizing the treatability and, hence, the degree of contaminant removal of raw water. The size of the SS has considerable impact on separation processes such as sedimentation, flocculation and filtration[2].

\subsection{Filter Media Alternative to Pebbles}

There are many types of media which can be used as alternatives to pebbles. Some of them are Quartz Sand, Silica Sand, Anthracite Coal, Garnet and Magnetite. According to research conducted at the Cambridge University with the aim of searching for an alternative to pebbles, a 100 year old brick factory near Sudbury, Suffolk has been found to produce hand-made clay pebbles satisfying the requirements of PMF. This was after several preliminary laboratory tests were conducted in Poland, Sri Lanka and Cambridge. For comparison purposes, the Cambridge experiments were conducted using clay pebbles made at the Bulmer Brick Company with two types of recycled crushed glass media[14].

As noted by Rajapakse et al.[14], results showed that new clay balls can be used as an alternative to natural pebbles, and that recycled glass performs as well as or even better than silica sand during the filtration process. Moreover, it was found that the head loss developed during clogging is about $30 \%$ higher for sand than for glass. Furthermore, cleaning the filter by drainage was more effective in the case of sand. However, it seems that the use of clay balls and recycled crushed glass as alternative media to natural pebbles was not feasible due to a number of reasons. For instance, a kiln with high temperature is required to produce clay balls which eventually would demand an additional cost for preparing specific sizes of clay balls with sufficient compressive strength.

Nevertheless up to date, a comprehensive research has not been conducted to evaluate the possibility of using burnt clay brick particles as an alternative filter media for PMF. 


\section{Research Methodology}

The methodology of this research consisted of a number of stages such as the construction of a model of the filter, preparation of filter materials, lab testing and data analysis.

\subsection{Construction of the Filter Model}

In order to conduct lab tests using different filter media configurations, a filter model was constructed using wood and fibre. The frame of the model was constructed using wood, and inside of the model was water sealed by means of a fibre layer.

The height, length and width of the model were $0.9 \mathrm{~m}, 0.6 \mathrm{~m}$ and $0.3 \mathrm{~m}$ respectively. The lower compartment of the model with $18 \mathrm{~cm}$ of height was to collect filtered water. The compartment located next to the weir of the model was to collect over flowing water above the weir (See Figure 2). Two circular pipes of $32 \mathrm{~mm}$ diameter with taps were connected at either side of the lower compartment, one as the effluent of the filtered water and the other as the effluent of the overflowed water. An iron mesh wrapped with linen net cloth was placed at the bottom of the upper compartment to accommodate easy passing of the filtered water into the lower compartment.

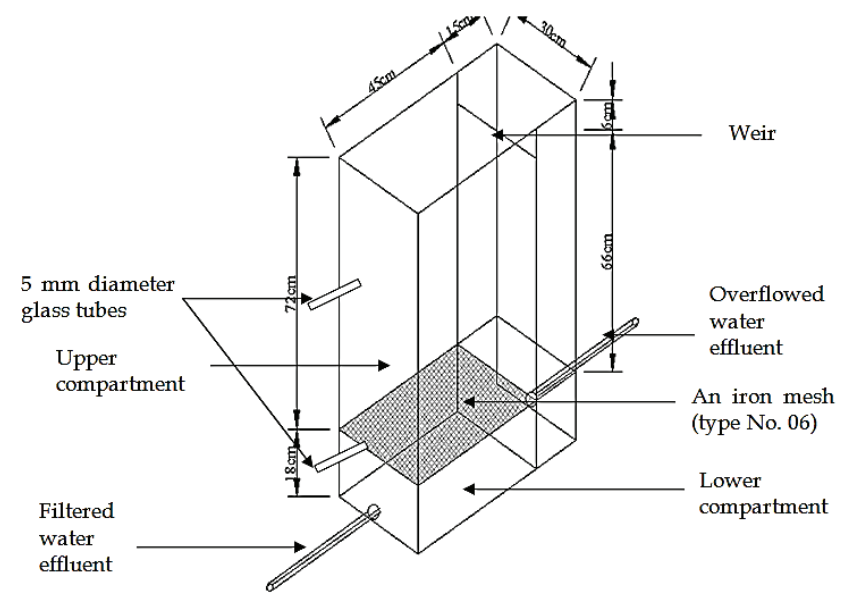

Figure 2 - Schematic Diagram of the Filter Model

For the purpose of measuring the head loss through the filter bed, a piezometer was arranged by means of two $5 \mathrm{~mm}$ diameter glass tubes with transparent rubber hoses which were attached to a vertical timber plate and fixed at the end of each tube at depths of $20 \mathrm{~cm}$ and $72 \mathrm{~cm}$ respectively from the top of the model.

\subsection{Preparation of Filter Materials}

As alternative filter materials, burnt bricks and chips were used due to their ready availability in Sri Lanka. Chips and brick particles were collected from construction sites to use as different filter media. In this research, river sand was mixed with selected alternative media to prepare the required filter media configurations (See Table 1).

Table 1-Details of Filter Media Configurations

\begin{tabular}{|c|c|c|c|}
\hline Configuration & Material & $\begin{array}{c}\text { Mean } \\
\text { Diameter } \\
\text { of the } \\
\text { Material } \\
(\mathrm{mm})\end{array}$ & $\begin{array}{c}\text { Material } \\
\text { :Sand } \\
\text { Ratio }\end{array}$ \\
\hline $\begin{array}{c}\text { Configuration } \\
1\end{array}$ & Chips & 5.14 & $1: 1$ \\
\hline $\begin{array}{c}\text { Configuration } \\
2\end{array}$ & Bricks & 50.00 & $1: 1$ \\
\hline
\end{tabular}

Initially, lab tests were conducted using chips after removing their impurities manually; and sieving them to sort out into different particle sizes. Firstly, particle sizes of required range were separated out. After sorting the chips at the initial stage, they were cleaned using water as shown in Figure 3. In order to obtain the particle size distribution and mean diameters of the different filer media configurations, the sieve analysis test was carried out based on the standard, BS 1377- Part 2 [7].

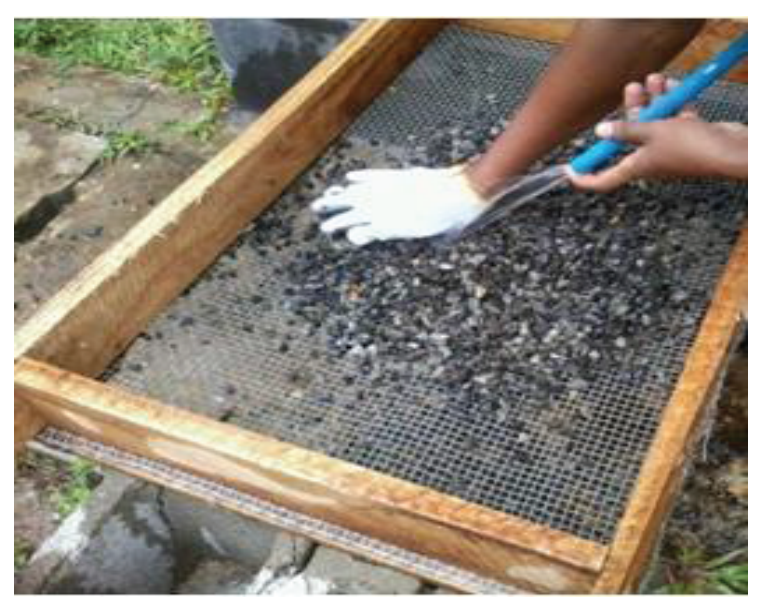

Figure 3 - Cleaning Procedure of Chips

After completing a series of tests on chips, tests were carried out for the brick particles. The size of the brick particles was selected to be approximately $50 \mathrm{~mm}$ as the use of small mean diameter brick particles was not practical due to the solubility effect of bricks. Impurities of brick particles were removed manually (See Figure 4). Large brick particles were broken 
using a hammer to prepare particles of the required size $(50 \mathrm{~mm})$. Brick particles were directly used without cleaning since they had fewer impurities compared to chips. Similarly, owing to the material loosing property of bricks, the sieve analysis test was not conducted on bricks, and the diameter range was determined using manual observations.

River sand was mixed with brick particles and chips in order to prepare the media-sand mixture required for the filter bed. At the end of every run, the filter media was taken out from the experimental setup and put into a bucket. Finally, the filter media was cleaned using a water jet. The cleaning procedure is described below:

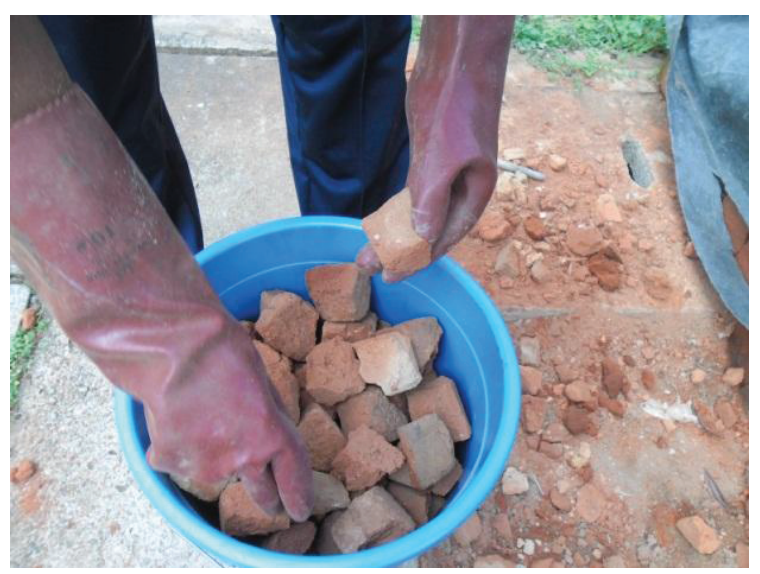

Figure 4 - Preparation of Brick Particles

A small quantity of chips was put at once on a sieve which had small openings. A water jet, created by squeezing the end of a rubber hose connected to a water tap, was pointed towards the top of the grains until dirt got washed off. Then, all were collected to the bucket which was then rotated until other solid-covered grains faced the water jet. This procedure was continued until all heavy deposits of turbid were washed out. Finally, the polishing stage was carried out by simultaneous scoop mixing and jet cleaning the chips. The cleaning operation ended once the drained water looked clear. However; large volumes of water were required in order to complete the cleaning operation.

\subsection{Lab Testing}

The purpose of the lab test was to identify from out of selected filter media configurations, the optimum filter media configuration that will reduce the turbidity of the influent water with high efficiency. There were three discrete layers in the experimental setup (See Figure 5). Filter media prepared outside was placed manually on the iron mesh of the filter model. Initially, a $60 \mathrm{~mm}$ thick layer of chips of $2-10 \mathrm{~mm}$ diameter was placed as a support layer for the second layer and the $300 \mathrm{~mm}$ second layer consisted of sand and selected filter media mixed into a 1:1 ratio. Previous research has found that the 1:1 ratio results in a more efficient filtration than the 3:2 ratio [15]. The top layer consisted of only selected filter media and had a thickness of $10 \mathrm{~mm}$. This filter media placement procedure was same for all configurations.

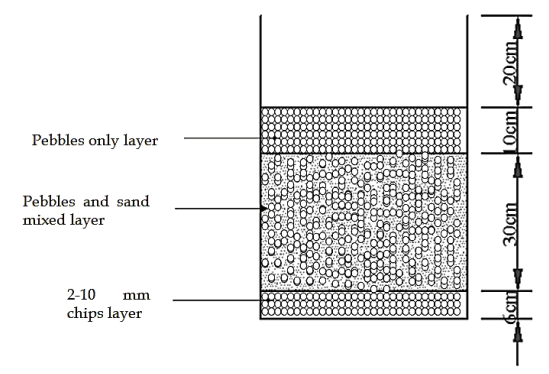

Figure 5 - Typical Arrangement of Filter Media

Initially, clean tap water of 0.56 NTU was sent as the influent while the filter model was continuously operated and, effluent turbidity was measured at every fifteen minutes. This was to further wash out all remaining turbid particles that were attached to the selected media (chips and bricks) and sand particles, and to prevent the contribution of those turbid particles to the effluent turbidity. It was clear that the effluent turbidity values obtained were entirely due to the remaining turbid particles of the influent after filtration. The filter model (See Figure 6) was operated at a filtration rate of 0.24 $\mathrm{m} / \mathrm{h}$. After the effluent turbidity became lower to reach the turbidity level of the tap water, the influent was shut off and the remaining water was gradually removed from the filter.

Thereafter, the influent turbidity was kept at 60 NTU in all experimental series. The filter media was operated for 3.5 hours while measuring the effluent turbidity at every fifteen minutes. The configuration that gave the highest turbidity removal efficiency was selected as the optimum configuration. Then, the selected optimum configuration was tested twice at each of the different influent turbidity values of 200 NTU, 300 NTU, 400 NTU and 500 NTU in order to observe the response of the selected configuration to high influent turbidity.

To conduct experimental runs, influent water was prepared by appropriately adding sieved clay into a bucket of tap water. The turbidity 
was measured using a HACH-2100P portable Turbidity Meter. The head loss of the filter model was monitored using a piezometer connected to it. The bucket with turbid water was placed $0.75 \mathrm{~m}$ above the top water level of the filter model. The influent to the filter model was provided using a $5 \mathrm{~mm}$ diameter transparent rubber hose that connected the turbid water bucket and the top of the filter model (See Figure 6).

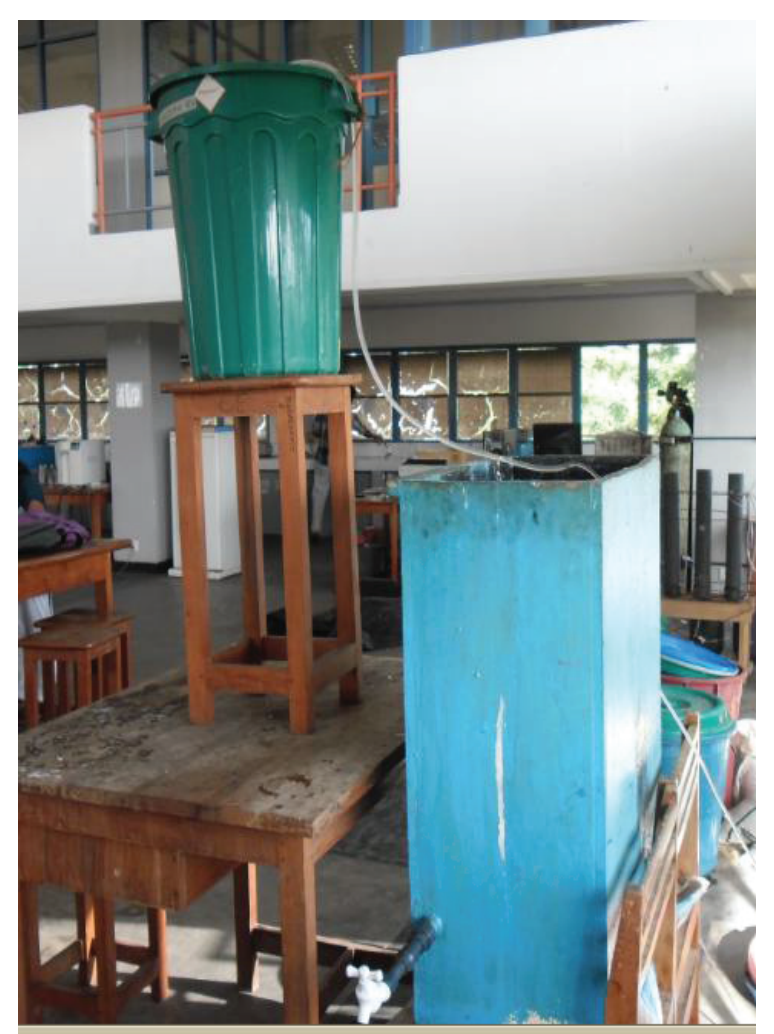

Figure 6 - The Experimental Setup

Continuous mixing was done throughout the test to maintain a homogenous condition and to keep turbid particles in suspension. The water level of the bucket was kept constant by continuously adding water at every five minutes. The influent flow rate was set to allow for the overflow of water over the weir into the adjacent apartment. This was to maintain a fixed head flow above the filter media.

\section{Results and Discussion}

Table 2 shows the test results for each configuration when influent turbidity was at 60 NTU. Test results showed that turbidity removal efficiencies of $75.17 \%$ and $79.33 \%$ were achieved by the two configurations. Configuration 2 was selected as the optimum configuration for giving the highest turbidity removal efficiency. The selected optimum filter media configuration was tested by changing the influent turbidity to 60 NTU, 200 NTU, 300 NTU, 400 NTU and 600 NTU as shown in Figure 7.

Table 2 - Test Results for Configuration 1 and Configuration 2 for an Influent Turbidity value of $60 \mathrm{NTU}$

\begin{tabular}{|c|c|c|c|c|c|c|c|}
\hline \multirow{2}{*}{$\begin{array}{c}\text { Filter } \\
\text { Media } \\
\text { Configu- } \\
\text { ration }\end{array}$} & \multirow{2}{*}{$\begin{array}{c}\text { Influent } \\
\text { Tur- } \\
\text { bidity } \\
\text { (NTU) }\end{array}$} & \multicolumn{4}{|c|}{$\begin{array}{l}\text { Minimum Effluent } \\
\text { Turbidity (NTU) }\end{array}$} & \multirow{2}{*}{$\begin{array}{c}\text { Turbid- } \\
\text { ity Re- } \\
\text { moval } \\
\text { Efficien- } \\
\text { cy }(\%)\end{array}$} & \multirow{2}{*}{$\begin{array}{l}\text { Total } \\
\text { Head } \\
\text { Loss } \\
(\mathrm{cm})\end{array}$} \\
\hline & & $\begin{array}{c}\text { Test } \\
1\end{array}$ & $\begin{array}{c}\text { Test } \\
2\end{array}$ & $\begin{array}{c}\text { Test } \\
3\end{array}$ & $\begin{array}{c}\text { Aver- } \\
\text { age }\end{array}$ & & \\
\hline $\begin{array}{l}\text { Configu- } \\
\text { ration } 1\end{array}$ & 60.0 & 13.6 & 15.0 & 16.2 & 14.9 & 75.2 & 6.1 \\
\hline $\begin{array}{l}\text { Configu- } \\
\text { ration } 2\end{array}$ & 60.0 & 11.6 & 12.8 & 12.8 & 12.4 & 79.3 & 6.0 \\
\hline
\end{tabular}

The short-term behaviour of effluent turbidity shows a slowly declining trend as time passes on. However, the effluent turbidity value remains approximately constant with time even nearly three hours after commencing the filtering operation. Similarly, a significant difference cannot be observed between the head loss development of two media configurations compared with the test results of previous research done using pebbles [15].

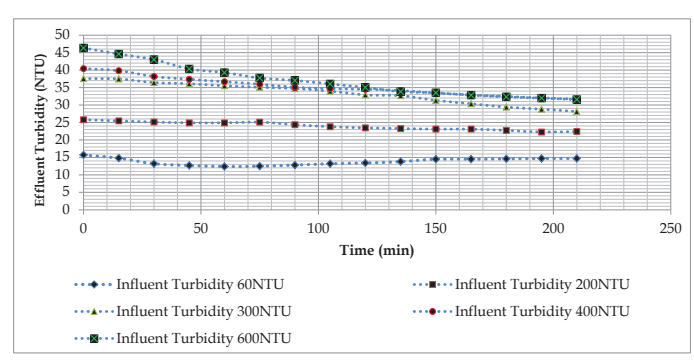

Figure 7 - Variation of Effluent Turbidity with Time for different Influent Turbidity Values of the considered Optimum Filter Media Configuration

Table 3 shows the variation of turbidity removal efficiency for the optimum configuration and for the mixed bed with a pebble: sand volume ratio of 1:1 for different influent turbidity values. The minimum turbidity removal efficiency of $79.4 \%$ was achieved when the influent turbidity was 60 NTU, with the least effluent turbidity produced at 12.4 NTU. When the influent turbidity was increased to $600 \mathrm{NTU}$, the efficiency was raised approximately up to $95 \%$ with an average effluent turbidity of 31.6 NTU.

The test results clearly show that the turbidity removal efficiency has increased with the increment of influent turbidity. This trend can be due to roughing filters with a large silt 
storage capacity, allowing for the deep penetration of suspended materials into the filter bed. A combination of gravitational settling and filtration takes place which gradually reduces the SS concentration once the raw water flows through a packed bed of coarse media. Moreover, frequent contacts amongst tiny suspended particles to form compacted settleable flocs were provided by the sinuous flow of the water through the voids of the coarse media. A part of the agglomerated flocs settle on the surface and within the openings of coarse media, which further aids in adsorbing finer particles as they contact with the settled flocs. As the flow emerges from the coarse media, agglomerated flocs settle on the top of the coarse media bed forming a layer of sludge blanket due to the sudden drop of velocity which is similarly effective in the removal of finer particles [4]. Thus, the total amount of silt or sludge storage blanket on top of the filter media layer becomes high when the influent turbidity is high. It eventually helps to further increase the turbidity removal efficiency.

Table 3 - Comparison of the Variation of Minimum Effluent Turbidity and Turbidity Removal Efficiency with Influent Turbidity

\begin{tabular}{|c|c|c|c|c|}
\hline \multirow[b]{2}{*}{$\begin{array}{l}\text { Influent } \\
\text { Turbidity } \\
\text { (NTU) }\end{array}$} & \multicolumn{2}{|c|}{ With Bricks: Sand 1:1 } & \multicolumn{2}{|c|}{ With Pebbles: Sand 1:1 } \\
\hline & $\begin{array}{c}\text { Average } \\
\text { Minimum } \\
\text { Effluent } \\
\text { Turbidity } \\
\text { (NTU) }\end{array}$ & $\begin{array}{c}\text { Turbidity } \\
\text { Removal } \\
\text { Efficiency } \\
(\%)\end{array}$ & $\begin{array}{l}\text { Average } \\
\text { Minimum } \\
\text { Effluent } \\
\text { Turbidity } \\
\text { (NTU) }\end{array}$ & $\begin{array}{c}\text { Turbidity } \\
\text { Removal } \\
\text { Efficiency } \\
(\%)\end{array}$ \\
\hline 60 & 12.40 & 79.34 & 5.90 & 90.18 \\
\hline 200 & 22.50 & 88.75 & 38.32 & 80.84 \\
\hline 300 & 28.10 & 90.64 & 70.10 & 76.63 \\
\hline 400 & 31.70 & 92.08 & 127.00 & 68.25 \\
\hline 600 & 31.60 & 94.74 & 206.21 & 65.63 \\
\hline
\end{tabular}

Conversely, according to the test results of a previous research which has been done with the same filter model under similar test conditions using pebbles of $7.2 \mathrm{~mm}$ mean diameter and a mixed bed with a pebble: sand volume ratio of $1: 1$, the effluent turbidity has increased once the influent turbidity was increased [16]Depending on the adsorption capacity of the filter media, the effluent turbidity can be increased as there is much adhesion to filter media due to the presence of a lot of turbid particles [17]. As a result of the low adsorption capacity of pebbles compared to that of bricks, the turbidity removal percentage has been decreased from $90.18 \%$ to $65.63 \%$ when influent turbidity was increased from 60 NTU to 600 NTU. Compared to pebbles, the brick particles perform efficiently and effectively in the turbidity removal process.

The results of previous research show that clay balls together with recycled crushed glass as an alternative to sand media in the PMF can be effective in turbidity removal. Recycled-crushed glass performed better than silica sand as an alternative fine media during the filtration process. In the tested inlet turbidity range of 78$589 \mathrm{NTU}$ and the filtration velocity range of $0.72-1.33 \mathrm{~m} / \mathrm{h}$, both glass and silica sand had removal efficiencies above 95\% [9]. As the brick particles provide a turbidity removal efficiency of around $90 \%$ for an inlet turbidity range of 200-600 NTU, brick particles can be considered as an effective and feasible alternative filter media for PMF.

\section{Summary and Conclusion}

Effective water treatment is the prime goal of every water treatment facility. However, the efficiency of the frequently used water treatment technique called SSF decreases during periods of heavy rain resulting in high turbidity water and causing disruption to continuous operations. Hence, the use of an effective pre-treatment method is crucial to protect the SSFs from high turbidity water. As a novel pre-treatment method, PMF technology has been used to treat high turbidity water during monsoonal periods.

However, sourcing the required size of pebbles as the filter media was challenging during the construction of the first full scale PMF plant built in Sri Lanka at Kataragama due to their scarcity, strict government regulations on pebble dredging and high cost.

In order to investigate possibilities of utilizing alternative filter media for PMF, laboratory tests were conducted using chips and burnt bricks as they were readily available in Sri Lanka. In this study, chips and bricks having mean diameters of $5.14 \mathrm{~mm}$ and $50 \mathrm{~mm}$ respectively and mixed separately with river sand having a mean diameter of $0.59 \mathrm{~mm}$ were used as filter media configurations. These two types of media configurations were individually tested using a laboratory filter column with sand in a 1:1 ratio. In this experimental investigation, the filter model was operated at a filtration rate of $0.16 \mathrm{~m} / \mathrm{h}$ and an influent turbidity of 60 NTU. 
Results showed that the short term behaviour of the effluent turbidity gradually declines with time. The effluent turbidity value remained constant with time approximately even three hours after commencing the filtering operation," and this phenomenon was identical in all tests. A turbidity removal efficiency of $75 \%$ was accomplished by chips with a mean diameter of $5.14 \mathrm{~mm}$ and for bricks with a $50 \mathrm{~mm}$ mean diameter it was $79 \%$. Similarly, there is no significant difference between head loss development of the two media configurations compared with test results of previous research done with pebbles.

It is clear that Configuration 2, namely, bricks with sand in 1:1 proportion have higher turbidity removal efficiency despite the higher mean diameter of the particles. Hence, Configuration 2 is the optimum filter media configuration and has been tested for higher turbidity values. It could be observed that turbidity removal efficiency increased with the increment of influent turbidity when the bricks were used as the filter media and for an influent turbidity of $60 \mathrm{NTU}$, the turbidity removal efficiency was about $79 \%$ while it increased to $94 \%$ when the influent turbidity was600 NTU. The effluent turbidity rose from 12.4 NTU to 31.6 NTU when the influent turbidity was increased from 60 NTU to 600 NTU.

The filtration efficiency of bricks generally increases when their mean diameter is decreased. However, the use of small mean diameter brick particles is not practical due to the solubility effect of bricks.

Results under this investigation indicate that broken-burnt bricks with sand in a 1:1 ratio have a greater potential as a pre-treatment media for turbidity removal. Moreover, bricks can be used as a viable alternative to natural pebbles which are currently used in pebble matrix filtration.

However, field trials at Kataragama WTP should commence in order to test the performance of the brick particles as an alternative filter media in PMF. It is equally important to verify the time taken to block the PMF and check the possibility of backwashing or cleaning effectively in a short time.

\section{References}

1. Gary, S. L., Water Filtration Practices: Including Slow Sand Filters and Precoat Filtration, 1st edition, Glacier Publishing Service, Inc., 2008, $72 \mathrm{p}$.

2. Takashi, A., Wastewater Reclamation and Reuse: Water Quality Management Library, Volume 10, CRC Press, London, 1998, 249p.

3. Gary, S. L., Water Filtration Practices: Including Slow Sand Filters and Precoat Filtration, 1st edition, Glacier Publishing Service, Inc., 2008, 218p.

4. APSU, The Sustainability of Arsenic Mitigation: A Survey of the Functional Status of Water Supplies, Arsenic Policy Support Unit, Dhaka, Bangladesh, 2006, 51p.

5. Rajapakse, J. P., Pre-filtration of High Turbidity Water, PhD Thesis, University of London, 1988

6. Lebcir, R., Factors Controlling the Performance of Horizontal Flow Roughing Filters, PhD Thesis, The University of Newcatle, 1992.

7. BS 1377-2:1990,Methods of test for Soils for Civil Engineering Purposes - Part 2: Classification tests, 1990.

8. Rajapakse, J. P., \& Ives, K. J., "Pre-filtration of Very Highly Turbid Waters using Pebble Matrix Filtration", Journal of IWEM, Volume 4, No 02, April, 1990, pp. 140-147

9. Rajapakse, J. P., \& Fenner, R. A., "Evaluation of Alternative Media for Pebble Matrix Filtration Using Clay Balls and Recycled Crushed Glass", Journal of Environmental Engineering- ASCE, Volume 137(6), June, 2011, pp. 517-524.

10. Catherine, N. M., Neginmalak, D., Masaharu, F., \& Tomohiro, I., Filtration of contaminated suspended solids for the treatment of surface water, Chemosphere, Volume 74, Issue 6, February, 2009, pp. 745-878.

11. Rajapakse, J. P., Jovanović, B., \& Ljubisavljević, D., "Field Trails of a Simple Surface Water Treatment Package for Rural Supply (Part II), Pebble Matrix Filtration Field Trials in Serbia and Montenegro." The Environment Engineer, Journal of the Society of Sustainability and Environmental Engineering, Institution of Engineers Australia, Volume 6, No 3, ISSN 14479435, Spring, 2005, pp.17- 19.

12. Ann, M. G., Dena, W. M., Doug P., \& Bruce, H., The effectiveness of slow sand filters to treat Canadian rural prairie water, Canadian Journal of Civil Engineering, Volume 38(4), 2011, pp. 455463. 
13. Rajapakse, J. P., Madabhushi, G., Fenner, R. \& Gallage, C., "Properties of Hand-Made Clay Balls used as a Novel Filter Media", Geomechanics and Engineering, Volume 4(4), 2012, pp. 281-294.

14. Rajapakse, J. P., Sumanaweera, S., Gallege, C. \& Thillainathan, V., "First Full Scale Trials of Pebble Matrix Filtration", Proceedings of the International Conference on Environment 2010 Green Technologies for the Benefits of Bottom Billions, Universiti Sains Malaysia, Penang, Malaysia, 2010.

15. Jayalath, C. P. G., Miguntanna, N.S., Samarasinghe, P. R .U. W., \& Kariyawasam, C.: Identification of Optimum Filter Media Configuration to Improve the Treatment Efficacy of Pebble Matrix Filters, Proceeding of SAITM Research Symposium on Engineering Advancements 2013, SAITAM-Faculty of Engineering, Sri Lanka, 2013, pp. 120-123.

16. Jayalath, C. P. G. \& Samarasinghe, P. R. U. W., Efficiency Improvement Methods to Pebble Matrix Filters (PMF), Undergraduate Research Thesis, University of Ruhuna, 2012.

17. Jahn, S. A., "Effectiveness of Traditional Flocculants as Primary Coagulants and Coagulants Aids for the Treatment of Tropical Raw Water with more than a Thousand-fold Fluctuation in Turbidity." Special Subject No. 615, IWSA congress, Monastir (Tunisia), 1984, pp. SS8-SS10. 